\title{
Multiple myeloma proteostasis can be targeted via translation initiation factor eIF4E
}

\author{
VICTORIA ZISMANOV ${ }^{1,4^{*}}$, OSHRAT ATTAR-SCHNEIDER ${ }^{1,4 *}$, MICHAEL LISHNER $^{1,2,4}$, \\ RACHEL HEFFEZ AIZENFELD ${ }^{3}$, SHELLY TARTAKOVER MATALON ${ }^{1,4}$ and LIAT DRUCKER ${ }^{1,4}$ \\ ${ }^{1}$ Oncogenetic Laboratory, ${ }^{2}$ Department of Internal Medicine, ${ }^{3}$ Geriatric Department, Meir Medical \\ Center, Kfar Saba; ${ }^{4}$ Sackler Faculty of Medicine, Tel Aviv University, Tel Aviv, Israel
}

Received July 29, 2014; Accepted September 11, 2014

DOI: $10.3892 /$ ijo.2014.2774

\begin{abstract}
Intensive protein synthesis is a unique and differential trait of the multiple myeloma (MM) cells. Previously we showed that tetraspanin overexpression in MM cell lines attenuated mTOR and PI3K cascades, induced protein synthesis, activated unfolded protein response (UPR), and caused autophagic death, all suggesting breach of proteostasis. Here we assessed the role of translation initiation in the tetraspanin-induced MM cell death with emphasis on eIF4E translation initiation factor. We showed tetraspanins attenuated peIF4E and its targets [c-Myc, cyclin D1 (cycD1)]; eIF4E attenuation was Akt-dependent. eIF4E inhibition in MM cells [bone marrow (BM), lines] by siRNA and/or the anti-viral drug and competitive eIF4E inhibitor ribavirin (RBV) deleteriously affected MM cells in a similar manner to the overexpression of tetraspanins. Furthermore, combined application of RBV and velcade had a synergistic anti-MM effect. Our results demonstrate that breach of proteostasis via eIF4E inhibition is an attractive therapeutic approach that may be relatively easily achieved by employing RBV, making this strategy readily translatable into the clinic.
\end{abstract}

\section{Introduction}

The malignant phenotype is characterized with extensive complexity that present a daunting problem with respect to treatment. Successful therapy depends on identification and targeting of critical functional nodes that will terminate the tumorigenic state by differentiation or death. This problem is definitely characteristic of the incurable multiple myeloma (MM), a malignancy of plasma cells that accumulate

Correspondence to: Dr Liat Drucker, Oncogenetic Laboratory, Meir Medical Center, 45 Tchernivoski Street, Kfar Saba 44281, Israel E-mail: druckerl@clalit.org.il

*Contributed equally

Key words: eIF4E, ribavirin, velcade, tetraspanins, CD81N1, CD82N1, Akt in the bone marrow (BM) (1). It is accepted that effectual MM treatment will need to address the cells in their supportive microenvironment as well as target compound signaling cascades so as to overcome cell heterogeneity and evolving resistance (1).

A unifying trait of MM cells is their extensive protein synthesis (2-4) supported by expanded endoplasmic reticulum (5) and activated unfolded protein response (UPR) pathways (6-8). Deregulation of protein synthesis has been linked to human cancers, MM included, with elevated global translation as well as increased synthesis of proteins integral to the malignant phenotype (4).

Protein synthesis is controlled by multiple stimuli primarily at the initiation level as observed under growth-promoting conditions and stress-induced synthesis shutdown (2,9-11). Translation initiation depends on recruitment of eukaryotic initiation complex eIF4F, which is composed of three proteins: the $5^{\prime}$ cap binding eIF4E, scaffolding protein eIF4G, and RNA helicase eIF4A. Many tumors, including subtypes of MM, display elevated levels of translation initiation factors $(3,4)$. Moreover, eIF4E overexpression induces malignant transformation and drug resistance (12), yet its knockdown (KD) selectively decreases translation of specific targets with no effect on global protein synthesis (11). Concordantly, the availability of eIF4E for capped mRNA translation dictates protein repertoire as well as synthesis rate (13). Regulation of eIF4E integrates metabolic and mitogenic cues with cell proliferation and growth (mTOR/4E-BP1 and PI3K/Ras/ERK/MNK). In fact, constitutive mitogenic activation of PI3K/Akt/mTOR (an established MM characteristic) in combination with activated Ras (detected in $\sim 50 \%$ of MM cases) $(2,14)$ may afford an explanation for elevated free eIF4E via mTOR/4E-BP1 and Ras/MNK/eIF4E phosphorylations in MM. Furthermore, several eIF4E targets are elevated in MM and may well be attributed to its enhanced activity: MMP9, Bcl2, BclXL, survivin, cyclin D1 (cycD1), c-Myc, and VEGF $(2,14)$. Interestingly, the frequent deregulation of c-Myc in MM can rarely be explained by translocation to an Ig locus; however elevated eIF4E translation could explain elevated c-Myc synthesis (15). If so, this could also feedback on eIF4E levels by increasing its transcription (15).

Previously, we demonstrated the downregulation of specific tetraspanin family members (CD81N1, CD82N1) in 
MM $(16,17)$. Tetraspanins are transmembrane proteins that orchestrate protein complexes thereby regulating proteins segregation and proximity and influencing fundamental biological processes, such as adhesion, migration, and proliferation. The expression of certain family members is correlated with malignant processes and prognosis $(18,19)$.

We also reported that overexpression of tetraspanin family members (CD81N1, CD82N1) normally silenced in myeloma, caused activation of UPR and autophagic death in MM cell lines, indicative of breached protein homeostasis (proteostasis) $(6,16,17)$. Recently, we showed that elevated protein synthesis induced by the overexpressed tetraspanins was instrumental in the MM cell death (20). We also observed an attenuation of eIF4E regulators, mTOR and PI3K signaling cascades yet elevated protein synthesis $(20,21)$. Hence, we speculated that protein synthesis regulated by these cascades might have been perturbed by CD81N1/CD82N1 and involved in determining the fate of MM cells. We investigated the tetraspanins' role in protein synthesis, particularly their effect on eIF4E. We proceeded to explore the efficacy of targeting eIF4E directly, to MM therapy.

\section{Materials and methods}

Cell lines and reagents. MM cell lines RPMI-8226, CAG, U266, ARP-1 and ARK were cultured in RPMI-1640 supplemented with $20 \%$ heat-inactivated FBS and antibiotics (Biological Industries, Kibbutz Beit-Haemek, Israel). RPMI-8226 constitutively expressing Akt was prepared by us previously (21) by stably transfecting Akt1/PKB $\alpha$ in pUSEamp or empty control vector (Millipore, Darmstadt, Germany) and selecting single cell clones with $1 \mathrm{mg} / \mathrm{ml} \mathrm{G} 418$ (Clontech, Mountain View, CA, USA). Cultured cells (20,000 cells/96-well culture plates) were treated with ribavirin (RBV) (0-7 $\mu \mathrm{M})$ (Sigma, St. Louis, MO, USA) diluted in water. We determined 5 days RBV IC50 (4.1 $\mu \mathrm{M}$ for RPMI-8226, 9.2 $\mu \mathrm{M}$ for CAG; Fig. 5). Velcade (bortezomib) from the oncologic pharmacy at Meir Medical Center was diluted in saline and used at $5 \mathrm{nM}$.

Study group. Eight peripheral blood samples obtained from healthy volunteers aged 45-80 years and 18 BM samples obtained from patients newly diagnosed (unless otherwise indicated) with MM were studied. Details regarding myeloma isotype, burden (\% monoclonal CD138 ${ }^{+}$plasma cells/BM aspirate mononuclear cells), light chain ratio $(\kappa / \lambda)$, and $\beta 2$ microglobulin levels are detailed in Table I. Blood and BM leucocytes were separated by Ficoll gradient (Sigma) according to manufacturer's instructions. The latter were hereafter regarded as mononuclear cells enriched with MM cells. Drug-treated BMs were cultured $\leq 5$ days in RPMI-1640 supplemented with 20\% heat-inactivated FBS and antibiotics. Lack of significant death under these conditions in control BM samples indicated that the experimental model was appropriate. B cells tagged with anti-CD19-Rd antibody (Dako, Glostrup, Denmark) were sorted from total blood leukocytes (BD FACSAria ${ }^{\mathrm{TM}}$ cell sorter; Tel Aviv University, Tel Aviv, Israel). The study was approved by Meir Medical Center Helsinki Committee, conducted according to Helsinki guidelines, and all participants signed informed consent forms.
Transient transfection of MM cell lines and constitutive Akt/empty RPMI-8226. Purified plasmids pEGFP-N1 (N1/Mock), CD81N1N1-eGFP (81N1) and CD82N1N1-eGFP (82N1) were separately introduced into RPMI-8226, CAG, constitutive Akt-RPMI-8226, orempty RPMI-8226asdescribed previously (17). Fluorescence ( $\geq 10,000$ events/analysis) was analyzed by flow cytometer (FACS) (EPICS XL; Beckman Coulter, Nyon, Switzerland) (17). Successful overexpression of CD81N1, CD82N1, and Akt in our models was demonstrated by us previously $(17,21)$. Transfected and untransfected cells were harvested $24 \mathrm{~h}$ post-transfection and stained with propidium iodide (PI) $(1 \mu \mathrm{g} / \mathrm{ml})$ for $10 \mathrm{~min}$. $\mathrm{PI}^{-} / \mathrm{PI}^{+}$cells were enumerated by $\mathrm{FACS}$. $\mathrm{PI}^{-}$or $\mathrm{eGFP}^{+} / \mathrm{PI}^{-}$were regarded as surviving cell fractions, whereas $\mathrm{PI}^{+}$and $\mathrm{eGFP}{ }^{+} / \mathrm{PI}^{+}$were regarded as dead cells. CD81N1N1/N1-transfected Akt/empty RPMI-8226 cells were harvested 19, 21 and $24 \mathrm{~h}$ post-transfection and assayed by immunoblotting for protein levels.

siRNA transfection. Validated Alexa-labeled AllStars negative control and eIF4E siRNAs (20 nM) (Qiagen, Valencia, CA, USA) were delivered into MM cell lines using DMRIE-C (Invitrogen Life Technologies, Carlsbad, CA, USA). Fluorescence ( $\geq 10,000$ events/analysis) was analyzed by FACS ( $\geq 95 \%$ ). Silencing of eIF4E was detected at the transcript level by qPCR. Tested time points included 24,48, 72,96 and $120 \mathrm{~h}$ post-transfection. All analyses of siRNA-transfected cells were done with unsorted cells.

Cell sorting. Transiently transfected cells (18/24 h post-transfection) or CD19-Rd-stained leucocytes were passed through a syringe for clump dispersion. $\mathrm{eGFP}^{+}$and $\mathrm{eGFP}^{-}$cells or $\mathrm{CD}^{+} 9^{+}$and $\mathrm{CD}^{-} 9^{-}$cells $\left(5 \times 10^{6}\right.$ cells $\left./ \mathrm{ml} 10 \% \mathrm{FBS}^{\mathrm{PBS}}\right)$ were collected (BD FACSAria ${ }^{\mathrm{TM}}$ cell sorter; Tel Aviv University). eGFP $^{-}$cells treated with transfection reagent only were used to calibrate the threshold of $\mathrm{eGFP}^{+}$cells.

Quantitative reverse transcription polymerase chain reaction $(R T-q P C R)$. Total RNA was extracted from $96 \mathrm{~h}$ siRNA-transfected cells with PARIS kit (Applied Biosystems, Carlsbad, CA, USA). RNA (1 $\mu \mathrm{g})$ was reverse transcribed (GeneAmp RNA PCR; Applied Biosystems) and amplified with QuantiFast SYBR-Green RT-PCR kit and eIF4E QuantiTect primers (cat. no. QT00046018; Qiagen) according to manufacturer's instructions. eIF4E expression was normalized to $\beta$-actin. A standard sample dilution series was executed with unknown samples for eIF4E and $\beta$-actin to verify the linearity of the results.

Viability and proliferation (WST-1) assay. Cell proliferation reagent WST-1 (Roche Diagnostics, Basel, Switzerland) was used according to manufacturer's instructions. Absorbancies measured by a scanning multiwell spectrophotometer (ELISA reader, model Sunrise; Tecan, Salzburg, Austria) were plotted on a linear scale. Cell survival was estimated as percentage of solvent-treated control values.

Apoptosis/necrosis analysis. Cells $\left(10^{6}\right)$ incubated with Annexin V-PE $(250 \mu \mathrm{g} / \mathrm{ml})$ (BioVision, Inc., Milpitas, CA, USA)/7AAD $(0.05 \mu \mathrm{g} / \mathrm{ml} / 15 \mathrm{~min})$ (eBioscience, San Diego, CA, USA) were analyzed by FACS. Apoptotic Annexin+7AAD and necrotic Annexin ${ }^{+} 7 \mathrm{AAD}^{+}$cells were enumerated. BM 
Table I. Clinical characteristics of the MM patients.

\begin{tabular}{|c|c|c|c|c|c|c|c|c|c|}
\hline $\begin{array}{l}\text { Patient } \\
\text { no. }\end{array}$ & Gender & $\begin{array}{c}\text { Age } \\
\text { (years) }\end{array}$ & Diagnosis & $\begin{array}{l}\text { Plasma cells in BM aspirate } \\
\text { mononuclear cells }(\%)\end{array}$ & $\begin{array}{c}\mathrm{CD} 138^{+} \text {of } \\
\text { plasma cells }(\%)\end{array}$ & \multicolumn{2}{|c|}{$\begin{array}{l}\text { Isotype } \\
\text { (g/dl) }\end{array}$} & $\begin{array}{l}\text { Light chain } \\
(\kappa / \lambda \text { ratio })\end{array}$ & $\begin{array}{l}\beta 2 \text { microglobulin } \\
(\mathrm{mg} / \mathrm{l})\end{array}$ \\
\hline 1 & M & 59 & MM & 13 & 97 & Нуро & & $\kappa 488$ & 4.1 \\
\hline 2 & M & 67 & MM & 20 & 90 & $\operatorname{Ig} \mathrm{A}$ & 3.1 & $\kappa 3.2$ & 2.1 \\
\hline 3 & M & 60 & MM & 70 & 99 & Нуро & & $\kappa 907$ & 1.2 \\
\hline 4 & M & 72 & MM & 40 & 89 & $\operatorname{IgA}$ & 4 & $\kappa 166$ & 4.7 \\
\hline 5 & M & 53 & MM & 30 & 92 & Normo & & $\lambda 0.02$ & 3.4 \\
\hline 6 & M & 68 & MM & 15 & 95 & $\mathrm{IgG}$ & 2.8 & $\kappa 11.4$ & 2.1 \\
\hline 7 & M & 75 & MM & 15 & NT & $\mathrm{IgG}$ & 2.9 & $\kappa 16.6$ & 5.8 \\
\hline 8 & M & 54 & MM & 80 & 95 & $\mathrm{IgG}$ & 3.6 & $\lambda 0.00$ & 5 \\
\hline 9 & $\mathrm{~F}$ & 50 & MM & 35 & 98 & Нуро & & $\lambda 0.00$ & NT \\
\hline 10 & $\mathrm{~F}$ & 55 & MM & 60 & 91 & $\operatorname{IgA}$ & 0.75 & $\lambda 0.06$ & 3.1 \\
\hline 11 & $\mathrm{~F}$ & 68 & MM & 30 & 55 & $\mathrm{IgG}$ & 3.5 & $\kappa 133$ & 2.2 \\
\hline 12 & $\mathrm{~F}$ & 62 & MM & 15 & 96 & $\mathrm{IgG}$ & 3 & $\lambda 0.01$ & 3.2 \\
\hline 13 & $\mathrm{~F}$ & 57 & SMM & 20 & NT & $\mathrm{IgG}$ & 3 & $\lambda 0.03$ & 2.7 \\
\hline 14 & $\mathrm{~F}$ & 54 & Relapse MM & 40 & 94 & Нуро & & $\lambda 0.00$ & 6.2 \\
\hline 15 & $\mathrm{~F}$ & 59 & SMM & 25 & 95 & $\mathrm{IgG}$ & 4.9 & $\kappa 6127$ & 2.5 \\
\hline 16 & $\mathrm{~F}$ & 52 & $\mathrm{MM}$ & 50 & 76 & Нуро & & $\lambda 0.00$ & 3.4 \\
\hline 17 & $\mathrm{~F}$ & 85 & MM & 35 & 94 & $\operatorname{Ig} \mathrm{A}$ & 0.85 & $\kappa 1.73$ & NT \\
\hline 18 & $\mathrm{~F}$ & 68 & MM & 50 & 93 & IgG & 2.6 & $\lambda 0.1$ & 3.5 \\
\hline
\end{tabular}

MM, multiple myeloma; BM, bone marrow; CD138, pathologic plasma cell marker (46); Normal $\kappa / \lambda$ ratio, 0.26-1.65 (47); Normal $\beta 2$ microglobulin <2 mg/l (47); M, male; F, female; SMM, smoldering multiple myeloma; NT, not tested; Hypo, hypogammaglobulinemia; Normo, normogammaglobulinemia.

MM samples were assayed for Annexin/7AAD in $\mathrm{CD}_{138^{+}}$cell fraction thereby addressing MM cells only.

Western blotting. Cells were lysed $10 \mathrm{~min}$ on ice (6). Protein samples $(300,000$ cells) mixed 1:5 with loading buffer were separated by SDS-PAGE and transferred to PVDF membrane. Membranes were blocked (5\% milk powder) and incubated with primary antibodies at $4{ }^{\circ} \mathrm{C}$ overnight. Rabbit anti-peIF4E (Ser209), total eIF4E, p4E-BP1 (Ser65), total 4E-BP1, pMNK1 (Thr197/Thr202), total MNK1, cycD1, BiP/GRP78 and mouse anti-c-Myc (1:1,000 dilution) were from Cell Signaling Technology, Inc. (Danvers, MA, USA). Rabbit anti-GADD153/CHOP (1:500) was from Santa Cruz Biotechnology, Inc. (Santa Cruz, CA, USA) and rabbit anti-ATF-6 (1:2,000) from Abcam (Cambridge, UK). The anti-pMNK1 antibody cross-reacts with pMNK2a and pMNK2b. Bound antibodies were visualized using peroxidase-conjugated secondary antibody (1:10,000, $75 \mathrm{~min}$ at $25^{\circ} \mathrm{C}$; Jackson ImmunoResearch Laboratories, West Grove, PA, USA) and ECL detection (Santa Cruz Biotechnology, Inc.). Products were visualized with LAS3000 Imager (Fujifilm, Greenwood, SC, USA). Integrated optical densities of immunoreactive protein bands were measured as arbitrary units employing Multi Gauge software (Fujifilm). All study results were normalized to cell number and tubulin-loading control.

Statistical analysis. Student's paired t-tests were used to analyze differences between cohorts. Effects were considered significant when $\mathrm{p} \leq 0.05$. An antagonistic effect was verified by drugs' interaction formula $\mathrm{q}=\mathrm{P}(\mathrm{A}+\mathrm{B}) / \mathrm{P}(\mathrm{A})+\mathrm{P}(\mathrm{B})-\mathrm{P}(\mathrm{A}) \mathrm{x}$ $\mathrm{P}(\mathrm{B})(\mathrm{q}<0.85$, antagonist; $\mathrm{q}>1.15$, synergist; $1.15>\mathrm{q}>0.85$, additive) (22). All experiments were conducted 3-7 separate times.

\section{Results}

Baseline expression of eIF4E in MM. We determined the expression and baseline levels of eIF4E protein in a panel of MM cell lines $(n=5)$ and BM mononuclear cells from MM patients $(n=18)$ compared to peripheral B cells from normal donors $(n=8)$. The comparison to normal peripheral B cells was implemented as done by others and us previously $(16,23)$ because normal plasma cells are not readily available and patients' BM samples were limited in volume due to prior use for medical purposes. This disallowed CD138 ${ }^{+}$cell sorting in quantities necessary for immunoblotting so we assayed BM mononuclear cells enriched with MM cells (Table I), as described in Materials and methods. We determined eIF4E is expressed in all specimens (immunoblot) (Fig. 1). Higher levels of total and phosphorylated eIF4E were observed in MM cells compared to B cells (cell lines: 2-fold change, BM samples: 10-fold change; $\mathrm{p}<0.05$ ) (Fig. 1). The differences in expression of phosphorylated and total eIF4E between MM cell lines and BM samples were also significant $(\mathrm{p}<0.05)$ and elaborated upon in the Discussion. These findings suggest a potential role for eIF4E in MM.

Tetraspanins attenuated levels of translation initiation factor eIF4E in MM cell lines. Next, we transiently transfected 

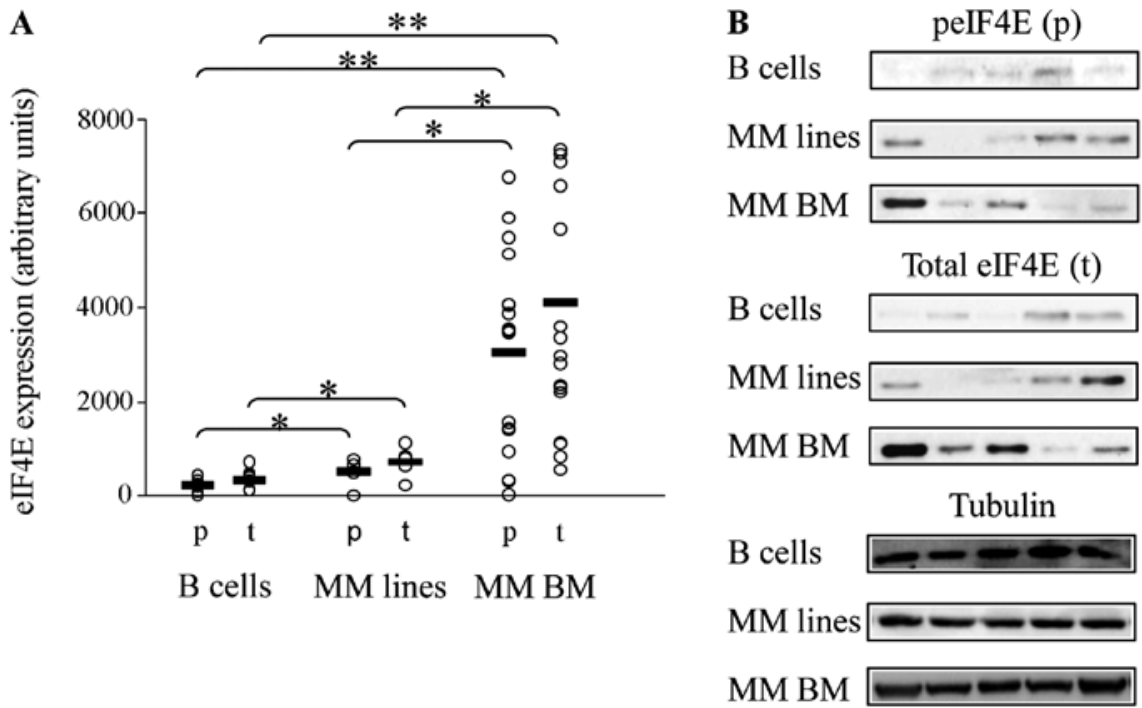

Figure 1. Baseline expression of eIF4E in B and multiple myeloma (MM) cells. (A) Graphic presentation and (B) representative immunoblots of expression of phosphorylated (p) and total ( $\mathrm{t}$ ) eIF4E in B cells $(n=8)$, MM cell lines $(n=5: 8226$, ARK, U266, ARP-1, CAG) and bone marrow $(B M)$ samples ( $n=18)$ of MM patients (x-axis) was detected by immunoblotting and expressed as arbitrary units (mean \pm SE) of immunoblotting densitometry. Each sample (normalized to cell number and tubulin) is indicated by an empty circle and group averages are depicted by a line. Statistically significant differences between cohorts $\left(\mathrm{p}<0.05,{ }^{* *} \mathrm{p}<0.01\right)$ are indicated.

CD81N1 and CD82N1 into MM cell lines (RPMI-8226, CAG). The actual overexpression of the tetraspanins was corroborated by flow cytometry (using anti-CD81N1 and anti-CD82N1 monoclonal antibodies) and microscopic analyses (17). Subsequently we assayed total and phosphorylated eIF4E protein levels in sorted CD81N1/CD82N1/Mock (N1)-transfected MM cell lines (RPMI-8226, CAG). A decrease in phosphorylated eIF4E protein levels was detected in the MM cell lines with both tetraspanin vectors $(\sim 60 \% \downarrow$ in RPMI-8226, 40\% in CAG, p<0.05) (Fig. 2A). The cell lines differed in the effect CD81N1 and CD82N1 had on total eIF4E levels. A decrease in total eIF4E level was determined in CAG transfected with CD81N1/CD82N1 ( 40\% $\downarrow$ and $\sim 15 \% \downarrow$, respectively, $\mathrm{p}<0.05)$ yet no change in its levels were seen in RPMI-8226 (Fig. 2A).

Then we examined the expression levels of major eIF4E regulators. Concordantly with the common tetraspanin-induced decrease in phosphorylated eIF4E we also determined a decrease in the phosphorylated active form of its kinase MNK1/2, in both cell lines (40-65\% $\mathrm{p}<0.05$ ) (Fig. 2B). Examination of the eIF4E-binding protein, 4E-BP1, uncovered significant changes in its expression following CD81N1/CD82N1 overexpression in both cell lines (Fig. 2B). RPMI-8226 was characterized with decreased phosphorylated 4E-BP1 in CD82N1 overexpressing cells $(32 \% \downarrow, p<0.05)$ but no change in CD81N1. CAG was typified by a decrease in the total 4E-BP1 levels with both tetraspanin vectors $(55-65 \% \downarrow, \mathrm{p}<0.05)$ without changes in phosphorylated 4E-BP1.

We examined the expression of known eIF4E targets in order to validate whether $\mathrm{CD} 81 \mathrm{~N} 1 / \mathrm{CD} 82 \mathrm{~N} 1$ indeed caused a reduction in eIF4E activity (Fig. 2C). A common reduction in cycD1 was observed in both cell lines with CD81N1 and CD82N1 (40-65\% t, $\mathrm{p}<0.05$ ) (Fig. 2C). Reduced expression of c-Myc was observed in CD81N1 transfected RPMI-8226 and CD81N1/CD82N1 transfected CAG (45-60\% $\downarrow$, p<0.05) (Fig. 2C).
Taken together, our findings so far indicate that the tetraspanins reduced the activity of the translation initiation factor eIF4E and its targets (Table II).

Constitutive Akt abrogatespeIF4Ereduction in CD81N1-transfected RPMI-8226 and rescues cells from consequent death. In a previous study we constructed and corroborated a multiple myeloma model expressing constitutive Akt (21). Furthermore, we have demonstrated the capability of constitutively active Akt to partially rescue the MM cell lines (RPMI-8226, CAG) from the tetraspanin (CD81N1/CD82N1)-induced death (21). Here we wanted to explore the possible involvement of eIF4E status in this phenomenon. Thus, we used the same model of control (empty vector-RPMI-8226) or stably transfected Akt-RPMI-8226 co-transfected with a Mock vector N1 or $\mathrm{CD} 81 \mathrm{~N} 1$, and re-assessed cell death and levels of peIF4E and $\mathrm{pMNK} 1 / 2$.

Increased peIF4E levels were observed in CD81N1-transfected Akt-RPMI-8226 compared to the CD81N1-transfected control empty vector-RPMI-8226 (105\% $\uparrow, p<0.05)$ (Fig. 3A). This was coupled with a definite rescue of the transfected cells from death (21) $(28 \%, \mathrm{p}<0.05)$. Analysis of the MM cells $3 \mathrm{~h}$ earlier, as described in Materials and methods, displayed elevated levels of pMNK1/2 in Akt-RPMI-8226 expressing CD81N1 cells relative to the empty vector-RPMI-8226 co-transfected with CD81N1 (18\%^, p<0.05) (Fig. 3B). The timing of elevated phosphorylated MNK1/2 is consistent with its position in the signaling cascade, downstream of Akt and upstream of eIF4E. These results demonstrate the co-regulation of survival and peIF4E levels in tetraspanin-overexpressing MM cell lines (Table II).

KD of eIF4E deleteriously affects MM cell lines. Next, we wanted to confirm directly that eIF4E activity is indeed critical to MM cell lines' growth and survival. Thus, we introduced anti-eIF4E siRNA into the MM cell lines ( $85 \%$ 
RPMI-8226

A

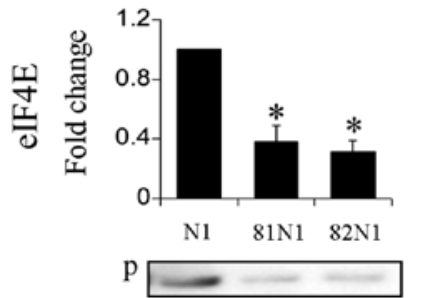

B

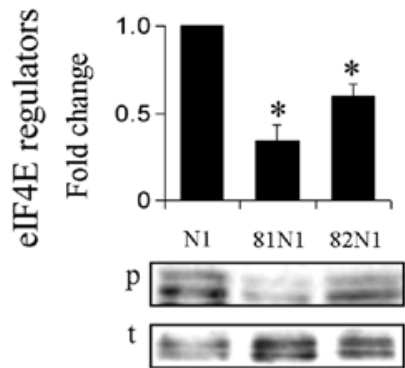

C

c-Myc (57-70 kDa)

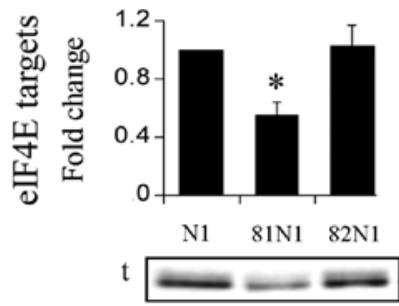

Total eIF4E (25 kDa)

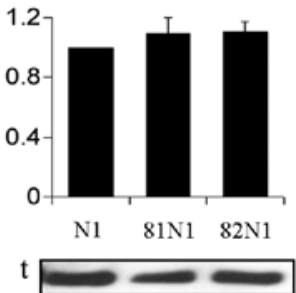

4E-BP1 (15-20 kDa)
CAG

peIF4E $(25 \mathrm{kDa})$

Total eIF4E (25 kDa)
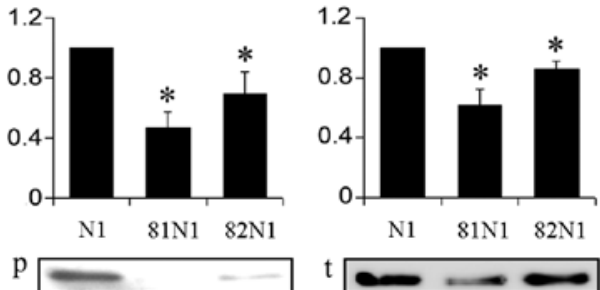

pMNK/MNK (50 kDa) 4E-BP1 (15-20 kDa)

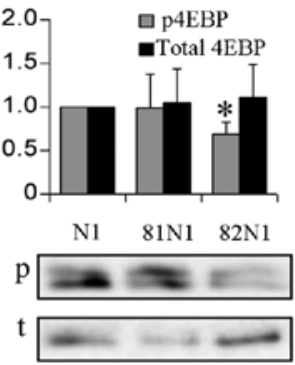

Cyclin D (36 kDa)
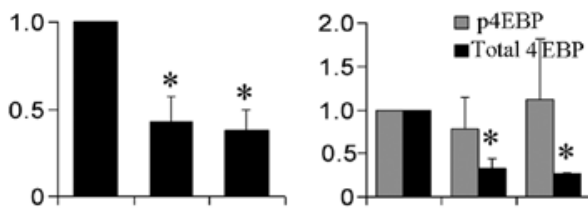

N1 $81 \mathrm{~N} 1 \quad 82 \mathrm{~N} 1$
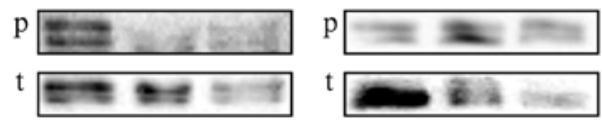

c-Myc (57-70 kDa)

Cyclin D (36 kDa)
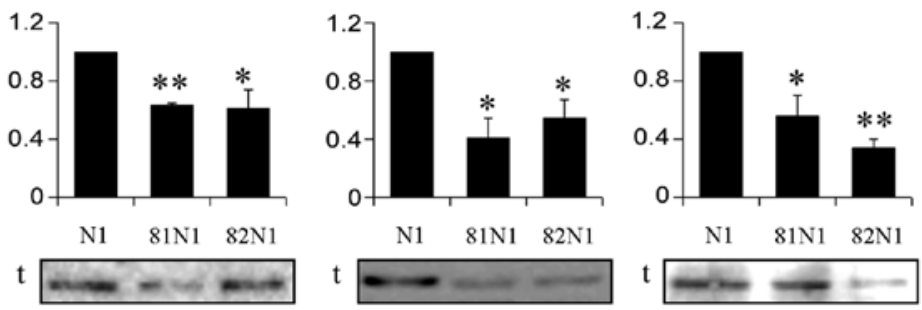

D

Ð
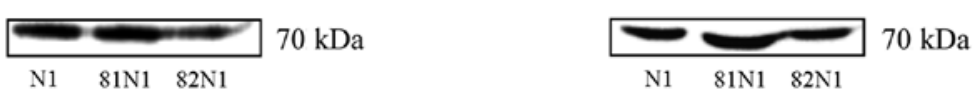

Figure 2. Tetraspanins attenuate levels of eIF4E in multiple myeloma (MM) cell lines. RPMI-8226 and CAG (depicted at the top) were transiently transfected with N1/Mock, CD81N1N1, or CD82N1N1. Representative immunoblots and graphic presentation (indicated at the top of each graph) (mean \pm SE, $\mathrm{n} \geq 3$ ) of (A) eIF4E [phospho (p), total (t)] densitometry, (B) its regulators MNK1/2, 4E-BP1 and (C) its targets c-Myc and cyclin D1 (cycD1) are presented. All protein quantities (normalized to cell number) were compared to corresponding quantitation in Mock transfected cell lines and presented as fold change. (D) Hsc70 served as a loading control and is presented for experiments conducted in RPMI-8226 and CAG, respectively. Statistically significant differences ( ${ }^{*} \mathrm{p}<0.05$, $\left.{ }^{* *} \mathrm{p}<0.01\right)$ are depicted.
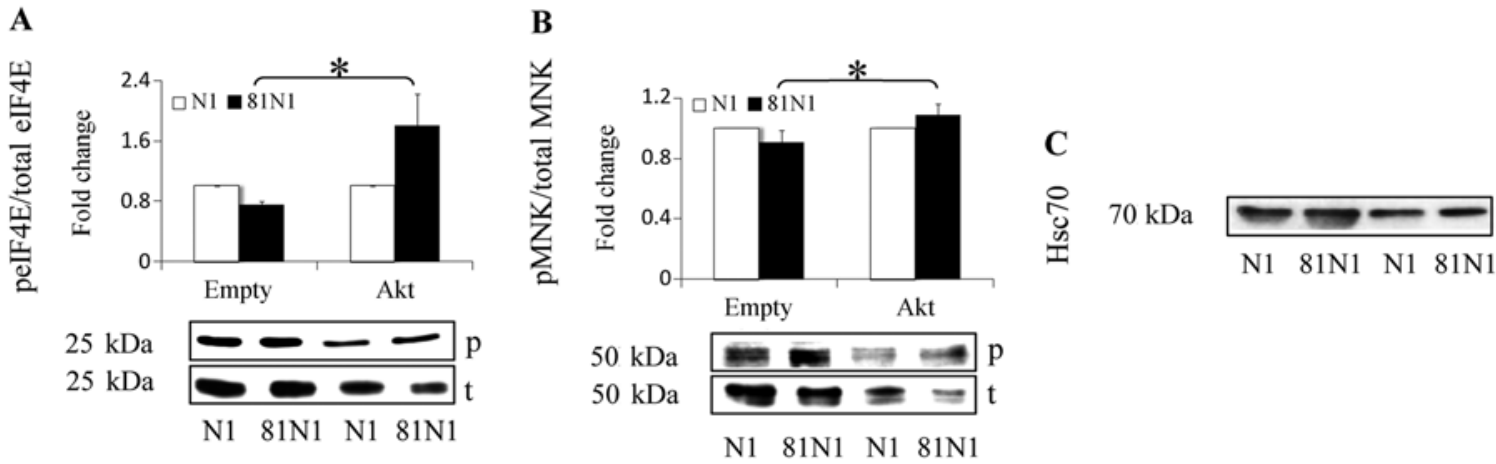

Figure 3. Constitutive Akt elevates peIF4E levels in CD81N1 transfected RPMI-8226. RPMI-8226 cells, constitutively expressing Akt or empty control vector, were also transiently transfected with N1/Mock or CD81N1. Graphic presentation (mean \pm SE, $\mathrm{n} \geq 3$, top) and representative immunoblots (bottom) of (A) phosho (p)-eIF4E/total (t) eIF4E and (B) phosho (p) MNK/total (t) MNK densitometry are presented. All protein quantities (normalized to cell number) were compared to quantification in corresponding Mock transfected cell lines and presented as fold change. Statistically significant differences $\left({ }^{*} \mathrm{p}<0.05\right)$ are indicated. At least three separate experiments in duplicate were conducted, and FACS recorded 10,000 events. (C) Hsc70 served as a loading control. It should be noted that the basal levels of eIF4E/MNK/Hsc70 expressions are lower in the Akt-expressing cells in comparison to the 8226 cells expressing the empty vector. 
Table II. Summary of the responses of MM cell lines to eIF4E modulation.

\begin{tabular}{|c|c|c|c|c|c|}
\hline \multirow[t]{3}{*}{ Assayed parameter } & & \multicolumn{4}{|c|}{ Model } \\
\hline & & \multicolumn{2}{|c|}{ RPMI-8226 } & \multicolumn{2}{|c|}{$\mathrm{CAG}$} \\
\hline & & CD81N1N1 & CD82N1N1 & CD81N1N1 & CD82N1N1 \\
\hline \multirow{6}{*}{$\begin{array}{l}\text { eIF4E, regulators } \\
\text { and targets }\end{array}$} & Phospho-eIF4E & $\downarrow$ & $\downarrow$ & $\downarrow$ & $\downarrow$ \\
\hline & Total eIF4E & $=$ & $=$ & $\downarrow$ & $\downarrow$ \\
\hline & 4E-BP1 & $=$ & $\downarrow$ & $\downarrow$ & $\downarrow$ \\
\hline & MNK1/2 & $\downarrow$ & $\downarrow$ & $\downarrow$ & $\downarrow$ \\
\hline & c-Myc & $\downarrow$ & $=$ & $\downarrow$ & $\downarrow$ \\
\hline & Cyclin D1 & $\downarrow$ & $\downarrow$ & $\downarrow$ & $\downarrow$ \\
\hline \multirow[t]{3}{*}{ Constitutive Akt } & peIF4E & $\uparrow$ & NT & NT & NT \\
\hline & $\mathrm{pMKN} 1 / 2$ & $\uparrow$ & NT & NT & NT \\
\hline & Rescue & $\checkmark^{\mathrm{a}}$ & $\sqrt{ }^{\mathrm{a}}$ & $\sqrt{ }^{\mathrm{a}}$ & $\sqrt{ }^{\mathrm{a}}$ \\
\hline \multirow[t]{2}{*}{ Treatment } & \multirow{2}{*}{$\begin{array}{l}\text { Assayed } \\
\text { parameter }\end{array}$} & \multicolumn{4}{|c|}{ Model } \\
\hline & & \multicolumn{2}{|c|}{ RPMI-8226 } & \multicolumn{2}{|c|}{ CAG } \\
\hline \multirow[t]{6}{*}{ siRNA eIF4E } & Cell count & \multicolumn{2}{|c|}{$=$} & \multicolumn{2}{|c|}{$\downarrow$} \\
\hline & Viability & \multicolumn{2}{|c|}{$\downarrow$} & \multicolumn{2}{|c|}{$\downarrow$} \\
\hline & Death & \multicolumn{2}{|c|}{$\uparrow$} & \multicolumn{2}{|c|}{$\uparrow$} \\
\hline & UPR & \multicolumn{2}{|c|}{$\uparrow$} & \multicolumn{2}{|c|}{$\uparrow$} \\
\hline & c-Myc & \multicolumn{2}{|c|}{$\downarrow$} & \multicolumn{2}{|c|}{$\downarrow$} \\
\hline & Cyclin D1 & \multicolumn{2}{|c|}{$\downarrow$} & \multicolumn{2}{|c|}{$\downarrow$} \\
\hline \multirow[t]{6}{*}{ Ribavirin } & Cell count & \multicolumn{2}{|c|}{$=$} & \multicolumn{2}{|c|}{$=$} \\
\hline & Viability & \multicolumn{2}{|c|}{$\downarrow$} & \multicolumn{2}{|c|}{$\downarrow$} \\
\hline & Death & \multicolumn{2}{|c|}{$=$} & \multicolumn{2}{|c|}{$=$} \\
\hline & UPR & & & & \\
\hline & $\mathrm{c}-\mathrm{Myc}$ & & & & \\
\hline & Cyclin D1 & & & & \\
\hline Ribavirin+Velcade & Cell count & & & & \\
\hline & Viability & & & & \\
\hline & Death & & & & \\
\hline & UPR & & & & \\
\hline
\end{tabular}

aLishner et al (21). MM, multiple myeloma; NT, not tested; UPR, unfolded protein response.

transfection in RPMI-8226, 95\% in CAG) and validated KD of eIF4E at 24 and 48 h post-transfection (RNA and protein, respectively, Fig. 4A). eIF4E KD was detected in unsorted cells by qPCR $(50 \% \downarrow$ in RPMI-8226 and CAG, p $<0.01$ and $\mathrm{p}<0.05$, respectively) and by immunoblotting (50\% in RPMI-8226, $\mathrm{p}<0.01$ and 60\% $\downarrow$ CAG, p<0.05) (Fig. 4A). We went on to assay the consequences of eIF4E KD on the expression of its dependent targets. Again, significant attenuation of cycD1 and c-Myc was observed in both cell lines $96 \mathrm{~h}$ post-transfection demonstrating that eIF4E activity was indeed compromised (30-40\% in RPMI-8226 and 30-35\% $\downarrow$ in CAG, $\mathrm{p}<0.01$ and $\mathrm{p}<0.05$, respectively) (Fig. 4C). Subsequently, we assessed the affect of eIF4E KD on the phenotype of MM cell lines 96-120 h post-transfection. Decreased viability was evidenced in both cell lines (96 h post-transfection: $20 \%$ in RPMI-8226; $10 \% \downarrow$ in CAG; $\mathrm{p}<0.05$ ). A decrease in cell count was also determined in CAG only ( $96 \mathrm{~h}$ post-transfection: $33 \% \downarrow$; $<0.05$ ). Analysis of cell death demonstrated moderately increased total cell death in both cell lines $96 \mathrm{~h}$ post-siRNA transfection in CAG and $120 \mathrm{~h}$ in 8226 (10-12\% $\mathrm{p}<0.01)$ attributed to apoptosis and necrosis (2-8\% $\uparrow$ apoptosis, $\mathrm{p}<0.01$ and $4-8 \% \uparrow$ necrosis, $\mathrm{p}<0.05$ ) (Fig. 4D, Table II). Higher death rates were evident in both cell lines at $120 \mathrm{~h}$ post-transfection $(15 \% \uparrow$ total death, $\mathrm{p}<0.01)$. Next, we assayed eIF4E KD on MM cell proteostasis by studying the expression of UPR proteins. A significant elevation of all UPR signaling arms (PERK, IRE1, and ATF-6 represented by CHOP, pJNK and ATF-6, respectively) was determined in both MM cell 
A

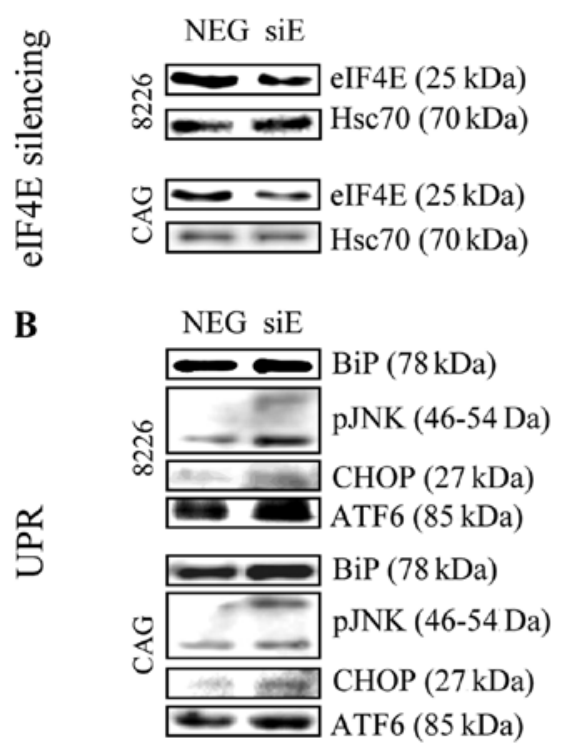

C
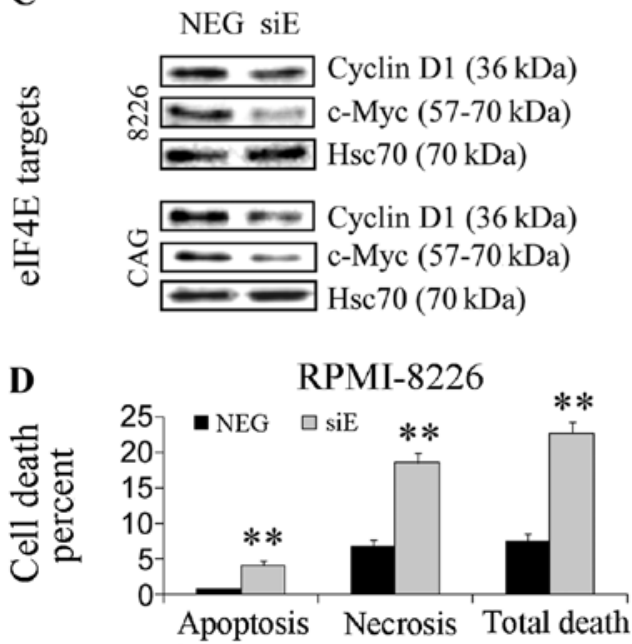

Fold change

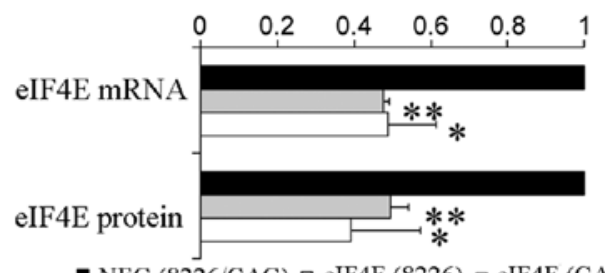

- $\operatorname{NEG}(8226 / \mathrm{CAG})$ 口 $\operatorname{eIF} 4 \mathrm{E}(8226)$ 口 $\operatorname{eIF} 4 \mathrm{E}(\mathrm{CAG})$

Fold change

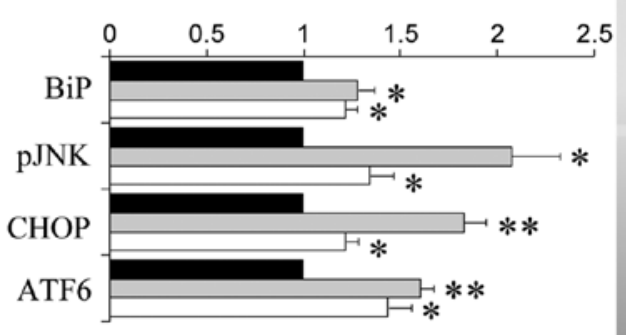

- NEG (8226/CAG) ם siE (8226) $\square \operatorname{siE}(\mathrm{CAG})$

Fold change

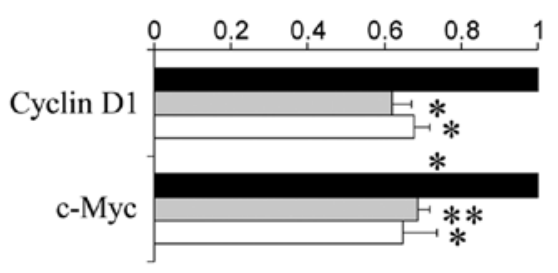

- NEG (8226/CAG) घ $\mathrm{siE}(8226) \square \mathrm{siE}(\mathrm{CAG})$

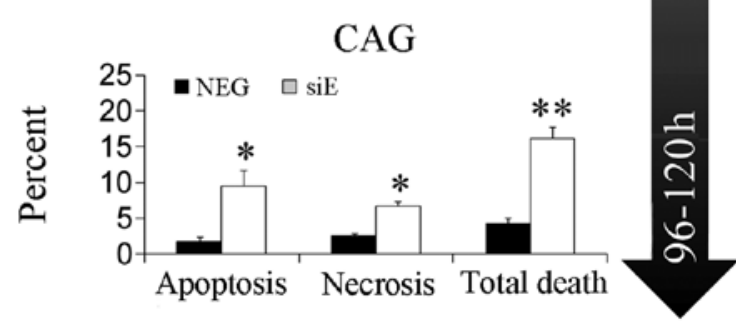

Figure 4. Knockdown (KD) of eIF4E deleteriously affects multiple myeloma (MM) cell lines. RPMI-8226 and CAG were transfected with negative siRNA control (NEG) or anti-eIF4E siRNA. Protein quantities were normalized to cell number and Hsc70 served as a loading control. All assayed parameters measured in siRNA eIF4E-transfected cells were compared to siRNA NEG transfected cells of the same line and expressed as fold change. Time line is depicted (right). Please notice that the data presented in chronological order and not as it appear in the text. (A) Silencing of eIF4E was detected at the transcript (qPCR) $(24 \mathrm{~h})$ and protein levels $(48 \mathrm{~h})$ [phospho (p), total (t)] (immunoblotting) and presented in representative immunoblots (left panel) and graphic presentations (mean \pm SE, n=3) (right panel). (B) eIF4E KD affected unfolded protein response (UPR) of MM cell lines CAG (24 h) and RPMI-8226 (48 h). Representative immunoblots (left panel) and graphic presentations (right panel) of UPR signaling arms are presented (mean \pm SE, $n=3)$. (C) Representative immunoblots (left panel) and graphic presentations of eIF4E targets (96 h) cyclin D1 (cycD1) and c-Myc are presented (mean \pm SE, $\mathrm{n}=3$ ) (right panel). (D) The effect of eIF4E KD on MM cell line death are graphically presented (CAG 96-120 h, RPMI-8226 120 h) (mean \pm SE, n=3). Statistically significant differences $\left(\mathrm{p}<0.05,{ }^{* *} \mathrm{p}<0.01\right)$ are depicted.

lines. RPMI-8226 displayed at $48 \mathrm{~h}$ post-transfection elevated

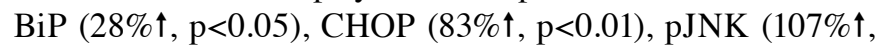
$\mathrm{p}<0.05)$, and ATF-6 (61\% $\uparrow, \mathrm{p}<0.01)$ (Fig. 4B). CAG displayed at $24 \mathrm{~h}$ post-transfection elevated $\mathrm{BiP}(22 \% \uparrow, \mathrm{p}<0.05), \mathrm{CHOP}$ $(22 \% \uparrow, \mathrm{p}<0.05), \mathrm{pJNK}(35 \% \uparrow, \mathrm{p}<0.05)$, and ATF-6 (44\% $\uparrow$, $\mathrm{p}<0.05$ ) (Fig. 4B). Taken together, these findings suggest that inhibition of eIF4E perturbs proteostasis in MM cell lines and enhances stress that leads to activation of the UPR.

Competitive inhibition of eIF4E with RBV elevates ER stress in $M M$ cell lines. Our findings so far indicate that eIF4E diminution may have anti-myeloma activity but the delivery of siRNA is currently clinically difficult. Therefore, we examined the effect of a clinically employed anti-viral drug, RBV suggested to act as a mimic for the $5^{\prime}$ cap present on most human transcripts thereby competing with eIF4E binding (24-27). RBV doses were calibrated and IC50 was determined for each cell line (Fig. 5), as described in Materials and methods. As hypothesized, RBV (5 $\mu \mathrm{M}, 5$ days) (24) caused decreased expression of eIF4Edependent targets cycD1 and c-Myc in both cell lines (15-35\% and 20-45\% $\downarrow$, respectively; p<0.05) (Fig. 6). Furthermore, RBV caused increased UPR signals indicative of elevated ER stress in RPMI-8226 (35\% $\uparrow \mathrm{BiP}, \mathrm{p}<0.01 ; 48 \% \uparrow \mathrm{pJNK}, \mathrm{p}<0.05)$ and CAG $(39 \% \uparrow \mathrm{BiP}, \mathrm{p}<0.05 ; 35 \% \uparrow \mathrm{pJNK}, \mathrm{p}<0.05 \%, 44 \% \uparrow \mathrm{CHOP}$, 


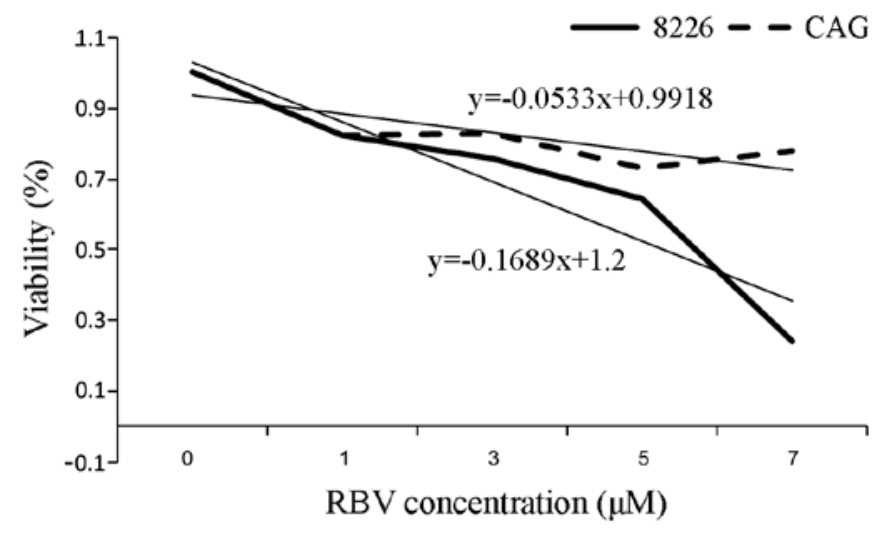

Figure 5. The dose response of MM cell lines to ribavirin (RBV). RPMI-8226 and CAG MM cell lines $(\mathrm{n}=3)$ were treated with escalating drug concentrations of RBV (0-7 $\mu \mathrm{M}, \mathrm{x}$-axis) for 5 days and assayed for viability detected with WST-1 cell proliferation assay. IC50 of RBV 5 days was established as $4.1 \mu \mathrm{M}$ for RPMI-8266 and $9.2 \mu \mathrm{M}$ for CAG.

p<0.01; 49\% $\uparrow$ ATF-6, p<0.05) (Fig. 7A, Table II). RBV also caused mild but significant reduction in the viability of MM cell lines $(10 \% \downarrow, \mathrm{p}<0.05)$. No biologically significant differences in cell counts or death were determined.

Combined RBV and velcade has anti-myeloma potential. Based on the observations we have made so far, we hypothesized that RBV may sensitize MM cells to drugs that induce ER-stress, such as velcade (bortezomib) $(28,29)$.

Indeed, in combined treatment of MM cell lines with $5 \mu \mathrm{M}$ $\mathrm{RBV}$ and $5 \mathrm{nM}$ velcade for 5 days we witnessed significantly increased UPR compared to the effect of each drug administered alone (RPMI-8226: $116 \% \uparrow \mathrm{BiP}, 107 \% \uparrow \mathrm{pJNK}, 50 \% \uparrow$ CHOP, 57\% ATF-6, p<0.05; CAG: 76\% $\uparrow \mathrm{BiP}, 57 \% \uparrow \mathrm{pJNK}$, $138 \% \uparrow \mathrm{CHOP}, 122 \% \uparrow$ ATF-6, $\mathrm{p}<0.05)$. This combined effect is synergistic $(q>1.15)$ or additive $(q=0.86)$ (Fig. 5A). RPMI-8226 and CAG treated with combined RBV and velcade also demonstrated reduced cell counts $(20 \% \downarrow, \mathrm{p}<0.05)$, reduced viability $(40-72 \% \downarrow, \mathrm{p}<0.05)$, and increased cell death $(63-75 \% \uparrow$, $\mathrm{p}<0.05$ ) (Fig. 6B, Table II) in comparison to each drug administered alone (synergistic, $\mathrm{q}>1.15$ ). Increased proliferation coupled with elevated death would result in minimal changes to steady state cell numbers yet higher extents of cell death.

Next, we administered RBV alone and in combination with velcade to primary mononuclear BM samples (enriched with MM cells) $(n=7)$. We ruled out the possibility that culture conditions caused decreased viability by demonstrating no decrease in control cells cultured up to 9 days (data not shown). Treatment of BM MM cells with combined RBV and velcade showed a significantly synergistic ( $\mathrm{q}>1.15)$ and additive $(\mathrm{q}=1)$ deleterious effect compared to the drugs administered individually (Fig. 7C). Particularly, this anti-myeloma response was evidenced in diminished cell counts $(35 \% \downarrow, \mathrm{p}<0.01)$, viability $(43 \% \downarrow, \mathrm{p}<0.01)$, and increased cell death in $\mathrm{CD} 138^{+}$ cell fraction (FACS) $(37 \% \uparrow, p<0.05)$.

\section{Discussion}

The premise of our study was that CD81N1N1/CD82N1N1 overexpression breached the proteostasis of MM cell lines,

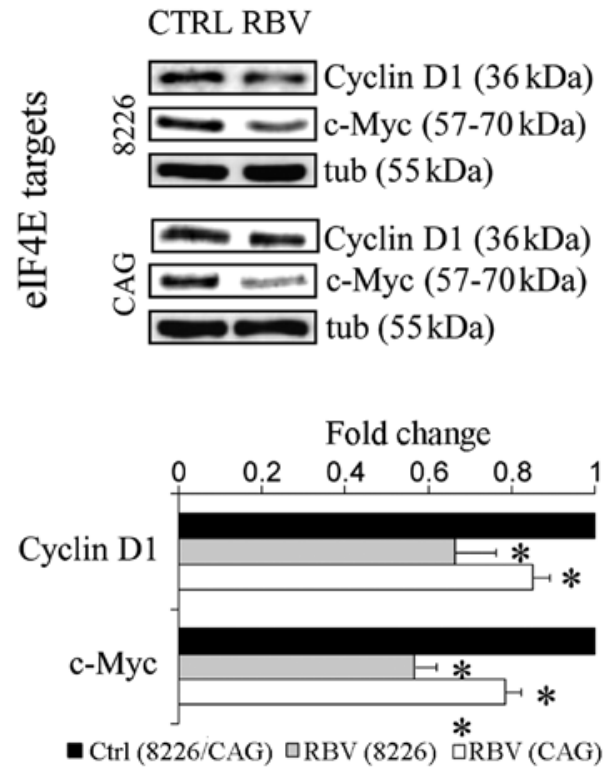

Figure 6. Ribavirin (RBV) decreases eIF4E-dependent targets in multiple myeloma (MM) cell lines. RPMI-8226 and CAG were treated with $5 \mu \mathrm{M}$ RBV or solvent. Representative immunoblots (top panel) and graphic presentations of fold change in densitometry (mean \pm SE, $n \geq 3$ ) (bottom panel) of eIF4E targets cyclin D1 (cycD1) and c-Myc in MM cell lines are presented. Protein quantities were normalized to cell number and tubulin (tub) served as a loading control. Statistically significant differences $\left({ }^{*} \mathrm{p}<0.05,{ }^{* *} \mathrm{p}<0.01\right)$ are indicated.

based on activation of UPR and induction of autophagic death (6). The increased fatal protein synthesis caused by the re-expression of tetraspanins (20) suggested that their natural downregulation in MM cells (16) may sustain specific 'proteostasis network' characteristics suited for the malignant cell survival and proliferation. Furthermore, the reduced mTOR and Akt signals in our research model (21) were consistent with altered eIF4E activity. Indeed, this study shows that CD81N1/CD82N1 transfection decreases eIF4E expression and function and may reaffirm that reduced CD81N1/CD82N1 in MM cells is instrumental to elevated eIF4E expression and beneficial to MM cells survival.

eIF4E expression was described previously in MM cells $(3,30)$ but to the best of our knowledge its importance was not addressed directly. We showed elevated expression of eIF4E in myeloma cells (BM samples and cell lines). Additionally, higher eIF4E levels were observed in BM myeloma cells compared to MM cell lines. This phenomenon may be attributed to signals originating from the BM microenvironment that affect eIF4E and are absent in cell culture.

The significance of eIF4E to myeloma cell survival and proliferation is evidenced in our study at multiple levels. We demonstrated that the expression of $\mathrm{c}-\mathrm{Myc}$ and cycD1 in RPMI-8226 and CAG is contingent on eIF4E activity. Both proteins are oncogenes overexpressed in $\mathrm{MM}$ and important to cell growth and survival. In many cases of MM there is no obvious mechanistic explanation for elevated c-Myc expression and our results may afford clarification of this issue $(2,14)$. The same is true for cases of elevated cycD1 that is not caused by Ig translocation. Interestingly, in a previous study conducted on the same model we showed that CD81N1N1/CD82N1N1 caused a decrease in MMP9, 
A

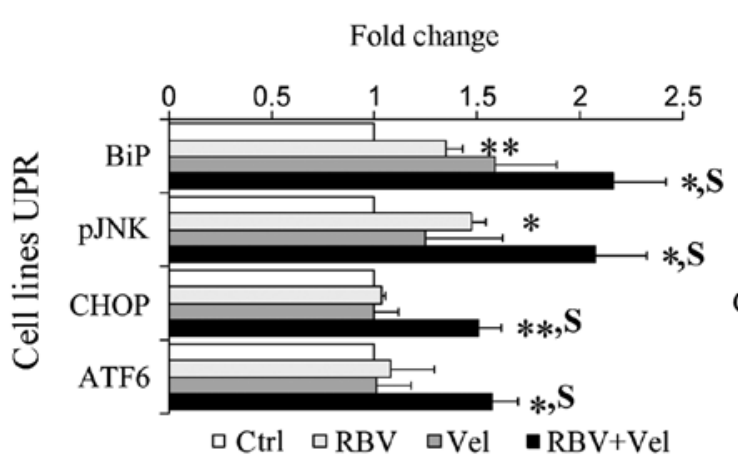

Ctrl RBV Vel RBV+Vel

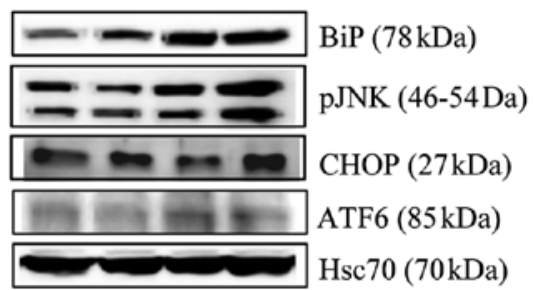

B

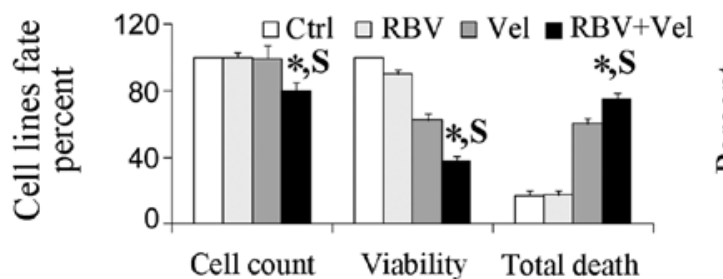

C

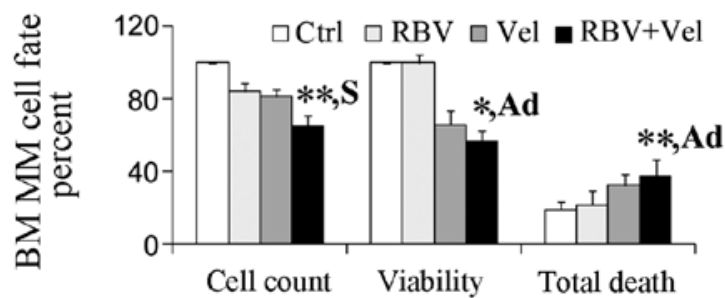

CAG

Fold change

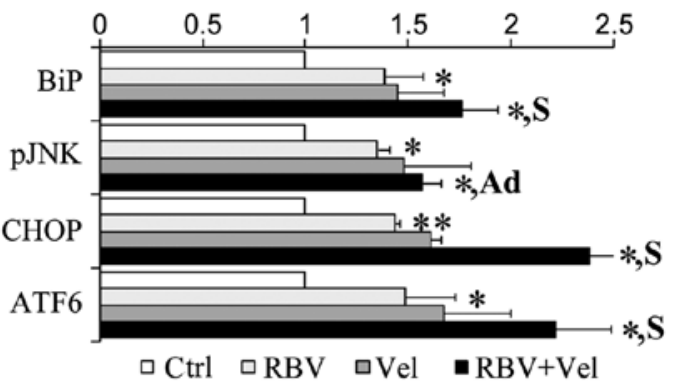

Ctrl RBV Vel RBV+Vel

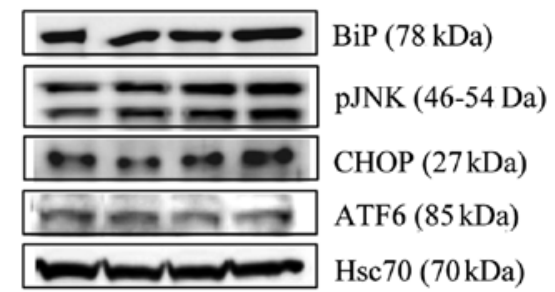

CAG

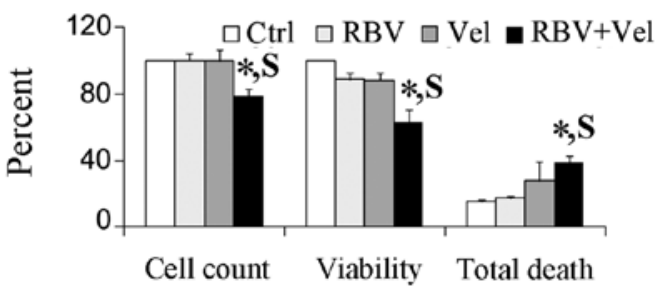

Figure 7. Combined ribavirin (RBV) and velcade (Vel) is advantageous in anti-myeloma treatment. Multiple myeloma (MM) cell lines and samples from bone marrow (BM) of MM patients were treated with solvent, $5 \mu \mathrm{M} \mathrm{RBV,} 5 \mathrm{nM}$ Vel or RBV and Vel combination. (A) Combined RBV and Vel-affected unfolded protein response (UPR) of MM cell lines. Representative immunoblots (bottom panel) and graphic presentations (top panel) of UPR signaling arms are presented (mean $\pm \mathrm{SE}, \mathrm{n} \geq 3$ ). Hsc70 served as a loading control. The effect of RBV and Vel treatment on (B) MM cell lines and (C) BM CD138 cell fraction count, viability, and death is graphically presented. All assayed parameters measured in treated cells were normalized to solvent treated control cells (mean $\pm \mathrm{SE}, \mathrm{n} \geq 3)$. Statistically significant differences $\left({ }^{*} \mathrm{p}<0.05,{ }^{* *} \mathrm{p}<0.01\right)$, synergistic $(\mathrm{S}, \mathrm{q}>1.15)$, and additive $($ Ad, $0.85<\mathrm{q}<1.15)$ effects of combined treatment are indicated.

which is also dependent on eIF4E $(17,31)$. Using constitutively expressing Akt-RPMI-8226 model we elaborated upon previous findings (21) and demonstrated that rescue from CD81N1-induced death is accompanied by increased eIF4E phosphorylation. We also showed elevated pMNK1/2. Taken together, these results suggest that the tetraspanins critically attenuate Akt activity, causing decreased pmTOR, pMNK1/2 and consequently diminished peIF4E levels.

siRNA and RBV mediated inhibition of eIF4E further stratified its importance to MM cell line growth and survival. This negative effect may be partially attributed to the downregulation of c-Myc and cycD1. Of note, while anti-eIF4E siRNA caused MM cell death RBV induced stress that did not result in death. Mechanistic differences may underlie this disparity since anti-eIF4E siRNA diminishes its expression, whereas RBV only abolishes its capped mRNAs' association thereby leaving eIF4E available for other cellular functions such as mRNA transport (32). The use of siRNA and a specific chemical inhibitor of eIF4E circumvent the limitations of the artificial tetraspanin overexpression model and confirm the accuracy of our findings. Moreover, our current observations and previously published data on the tetraspanin-induced changes in the MM cell line model all support the deduction that the regulation of proteostasis is critically important to survival of MM cell lines and that eIF4E expression level is instrumental to this equilibrium. A reasonable assumption 
is that the tetraspanin-induced death of the MM cell lines is a sum consequence of the compiled effects as previously reported $(6,20,21)$.

Our findings regarding eIF4E regulation comply with published data and substantiate a role for both Ras/MNK and mTOR/4E-BP1 (33). It is established that eIF4E phosphorylation is carried out by $\mathrm{MNK} 1 / 2$, and indeed we witnessed reduced phosphorylated $\mathrm{MNK} 1 / 2$ in concordance with reduced phosphorylated eIF4E with both tetraspanin vectors in both MM cell lines (33). The role of 4E-BP1 is more complex. On the one hand, it binds eIF4E in the cytoplasm thereby preventing its inclusion in the translation initiation factor eIF4F (10), on the other hand, it has been shown to be instrumental to nuclear compartmentalization of eIF4E, where the translation factor promotes export of specific mRNAs to the cytoplasm for translation $(34,35)$. It was shown that fully phosphorylated 4E-BP1, manifested in phosphorylated serine 65 residues, releases eIF4E (10). Free eIF4E is phosphorylated and activated or ubiquitinated and degraded (10). We showed MM cell lines displayed different regulatory mechanisms where 4E-BP1 is concerned. RPMI-8226 displayed stable total eIF4E levels probably due to increased protective binding to un-phosphorylated 4E-BP1. CAG demonstrated decreased total eIF4E levels possibly explained by the significantly depleted 4E-BP1 levels. Regulation of 4E-BP1 by degradation was published in a model of sea urchins (36).

Recently, we reported that tetraspanins affect global protein synthesis (20), yet to the best of our knowledge this is the first account linking tetraspanins to specific mechanisms regulating the process. Previous studies described association of tetraspanin members with cell proliferation and production of specific proteins failed make a more general connection to cell proteostasis (37-39). Most interesting are publications that described the tetraspanin influence on expression of proteins that can now be categorized as eIF4E-dependent targets (40-42). Available therapeutic approaches unbalance proteostasis by limiting protein synthesis and availability or affecting protein degradation. Our results present a tetraspanin-dependent attenuation of eIF4E as a means to critically unbalancing myeloma cell proteostasis.

An unresolved conundrum is the conflicting observations we have made that on the one hand tetraspanins elevate global protein synthesis (20) yet on the other hand cause decrease of eIF4E levels and activity. While these findings are in concordance with eIF4E KD studies that showed global protein synthesis is unaffected (43) we cannot currently explain by what mechanism the tetraspanins promote protein production. Current studies underway in our laboratory are exploring the possible involvement of eIF4GI on the effect of tetraspanins.

Altogether, our results demonstrate that targeting eIF4E in MM has therapeutic potential. This is especially promising due to the various publications proclaiming that the initiation factor is overexpressed in cancer cells, affording a certain advantage in terms of selectivity. This approach is clinically more feasible with the use of RBV, as we had shown since it is a widely prescribed anti-viral drug and has limited and treatable side-effects (44). The efficacy of this strategy was previously demonstrated in acute myeloid leukemia and in head and neck cancer $(45,46)$. Interestingly, a recently published case report described regression of myeloma in a patient treated with
RBV for HCV infection (47). The advantageous combination of RBV and velcade affords proof-of-concept to the potential utility of simultaneously targeting various proteostasis arms in MM treatment.

\section{Acknowledgements}

This study constitutes sections of the Ph.D. theses of Victoria Zismanov and Oshrat Attar-Schneider, Sackler Faculty of Medicine, Tel Aviv University, Israel. Victoria Zismanov and Oshrat Attar-Schneider contributed equally to the research and preparation of the manuscript. We are grateful to the staff of the Hematological Laboratory at Meir Medical Center for their dedicated technical support. This study was supported by the Tel Aviv University Research Grant no. 0601242791.

\section{References}

1. Anderson KC: Targeted therapy of multiple myeloma based upon tumor-microenvironmental interactions. Exp Hematol 35 (Suppl 1): S155-S162, 2007.

2. Pratt G: Molecular aspects of multiple myeloma. Mol Pathol 55: 273-283, 2002.

3. Agnelli L, Fabris S, Bicciato S, et al: Upregulation of translational machinery and distinct genetic subgroups characterise hyperdiploidy in multiple myeloma. Br J Haematol 136: 565-573, 2007.

4. Barnhart BC and Simon MC: Taking aim at translation for tumor therapy. J Clin Invest 117: 2385-2388, 2007.

5. Cenci $S$ and Sitia R: Managing and exploiting stress in the antibody factory. FEBS Lett 581: 3652-3657, 2007.

6. Zismanov V, Lishner M, Tartakover-Matalon S, Radnay J Shapiro H and Drucker L: Tetraspanin-induced death of myeloma cell lines is autophagic and involves increased UPR signalling. Br J Cancer 101: 1402-1409, 2009.

7. Carrasco DR, Sukhdeo K, Protopopova M, et al: The differentiation and stress response factor XBP-1 drives multiple myeloma pathogenesis. Cancer Cell 11: 349-360, 2007.

8. Patterson J, Palombella VJ, Fritz C and Normant E: IPI-504, a novel and soluble HSP-90 inhibitor, blocks the unfolded protein response in multiple myeloma cells. Cancer Chemother Pharmacol 61: 923-932, 2008.

9. Larsson O, Li S, Issaenko OA, et al: Eukaryotic translation initiation factor 4E induced progression of primary human mammary epithelial cells along the cancer pathway is associated with targeted translational deregulation of oncogenic drivers and inhibitors. Cancer Res 67: 6814-6824, 2007.

10. Wang X and Proud CG: Methods for studying signal-dependent regulation of translation factor activity. Methods Enzymol 431: 113-142, 2007.

11. Montanaro L and Pandolfi PP: Initiation of mRNA translation in oncogenesis: the role of eIF4E. Cell Cycle 3: 1387-1389, 2004.

12. Wu KD, Zhou L, Burtrum D, Ludwig DL and Moore MA: Antibody targeting of the insulin-like growth factor I receptor enhances the anti-tumor response of multiple myeloma to chemotherapy through inhibition of tumor proliferation and angiogenesis. Cancer Immunol Immunother 56: 343-357, 2007.

13. Ramirez-Valle F, Braunstein S, Zavadil J, Formenti SC and Schneider RJ: eIF4GI links nutrient sensing by mTOR to cell proliferation and inhibition of autophagy. J Cell Biol 181: 293-307, 2008.

14. Kastrinakis NG, Gorgoulis VG, Foukas PG, Dimopoulos MA and Kittas C: Molecular aspects of multiple myeloma. Ann Oncol 11: 1217-1228, 2000.

15. Lin CJ, Cencic R, Mills JR, Robert F and Pelletier J: c-Myc and eIF4F are components of a feedforward loop that links transcription and translation. Cancer Res 68: 5326-5334, 2008.

16. Drucker L, Tohami T, Tartakover-Matalon S, et al: Promoter hypermethylation of tetraspanin members contributes to their silencing in myeloma cell lines. Carcinogenesis 27: 197-204, 2006.

17. Tohami T, Drucker L, Shapiro H, Radnay J and Lishner M: Overexpression of tetraspanins affects multiple myeloma cell survival and invasive potential. FASEB J 21: 691-699, 2007. 
18. Lazo PA: Functional implications of tetraspanin proteins in cancer biology. Cancer Sci 98: 1666-1677, 2007.

19. Charrin S, le Naour F, Silvie O, Milhiet PE, Boucheix C and Rubinstein E: Lateral organization of membrane proteins: tetraspanins spin their web. Biochem J 420: 133-154, 2009.

20. Zismanov V, Drucker L, Attar-Schneider O, Matalon ST, Pasmanik-Chor $M$ and Lishner M: Tetraspanins stimulate protein synthesis in myeloma cell lines. J Cell Biochem 113: 2500-2510, 2012.

21. Lishner M,Zismanov V, Tohami T, Tartakover-Matalon S, Elis A and Drucker L: Tetraspanins affect myeloma cell fate via Akt signaling and FoxO activation. Cell Signal 20: 2309-2316, 2008

22. Su DF, Xu LP, Miao CY, Xie HH, Shen FM and Jiang YY: Two useful methods for evaluating antihypertensive drugs in conscious freely moving rats. Acta Pharmacol Sin 25: 148-151, 2004.

23. Thiago LS, Perez-Andres M, Balanzategui A, et al: Circulating clonotypic B cells in multiple myeloma and monoclonal gammopathy of undetermined significance. Haematologica 99: 155-162, 2014.

24. Assouline S, Culjkovic B, Cocolakis E, et al: Molecular targeting of the oncogene eIF4E in acute myeloid leukemia (AML) a proof-of-principle clinical trial with ribavirin. Blood 114: 257-260, 2009

25. Matassa DS, Amoroso MR, Agliarulo I, et al: Translational control in the stress adaptive response of cancer cells: a novel role for the heat shock protein TRAP1. Cell Death Dis 4 e851, 2013

26. Issur M, Bougie I, Despins S and Bisaillon M: Enzymatic synthesis of RNAs capped with nucleotide analogues reveals the molecular basis for substrate selectivity of RNA capping enzyme: impacts on RNA metabolism. PLoS One 8: e75310, 2013.

27. Tan K, Culjkovic B, Amri A and Borden KL: Ribavirin targets eIF4E dependent Akt survival signaling. Biochem Biophys Res Commun 375: 341-345, 2008

28. Mujtaba T and Dou QP: Advances in the understanding of mechanisms and therapeutic use of bortezomib. Discov Med 12: 471-480, 2011

29. Moriya S, Che XF, Komatsu S, et al: Macrolide antibiotics block autophagy flux and sensitize to bortezomib via endoplasmic reticulum stress-mediated CHOP induction in myeloma cells. Int J Oncol 42: 1541-1550, 2013.

30. Attar-SchneiderO,Drucker L,Zismanov V,Tartakover-Matalon S, Rashid $\mathrm{G}$ and Lishner $\mathrm{M}$ : Bevacizumab attenuates major signaling cascades and eIF4E translation initiation factor in multiple myeloma cells. Lab Invest 92: 178-190, 2012.

31. Graff JR and Zimmer SG: Translational control and metastatic progression: enhanced activity of the mRNA cap-binding protein eIF-4E selectively enhances translation of metastasis-related mRNAs. Clin Exp Metastasis 20: 265-273, 2003.
32. Culjkovic B, Topisirovic I, Skrabanek L, Ruiz-Gutierrez M and Borden KL: eIF4E promotes nuclear export of cyclin D1 mRNAs via an element in the 3'UTR. J Cell Biol 169: 245-256, 2005.

33. Wang $X$, Yue $P$, Chan CB, et al: Inhibition of mammalian target of rapamycin induces phosphatidylinositol 3-kinase-dependent and Mnk-mediated eukaryotic translation initiation factor 4E phosphorylation. Mol Cell Biol 27: 7405-7413, 2007.

34. Livingstone $M$, Larsson O, Sukarieh R, Pelletier J and Sonenberg N: A chemical genetic screen for mTOR pathway inhibitors based on 4E-BP-dependent nuclear accumulation of eIF4E. Chem Biol 16: 1240-1249, 2009.

35. Rong L, Livingstone M, Sukarieh R, et al: Control of eIF4E cellular localization by eIF4E-binding proteins, 4E-BPs. RNA 14: 1318-1327, 2008.

36. Saad H, Bellé R, Morales J, et al: Initiation factors eIF4: from sea urchin embryonic development to chronic lymphocytic leukemia. J Soc Biol 201: 307-315, 2007 (In French).

37. Saito Y, Tachibana I, Takeda Y, et al: Absence of CD9 enhances adhesion-dependent morphologic differentiation, survival, and matrix metalloproteinase-2 production in small cell lung cancer cells. Cancer Res 66: 9557-9565, 2006.

38. Hasegawa M, Furuya M, Kasuya Y, et al: CD151 dynamics in carcinoma-stroma interaction: integrin expression, adhesion strength and proteolytic activity. Lab Invest 87: 882-892, 2007.

39. Maecker HT: Human CD81 directly enhances Th1 and Th2 cell activation, but preferentially induces proliferation of Th2 cells upon long-term stimulation. BMC Immunol 4: 1, 2003.

40. Zöller M: Tetraspanins: push and pull in suppressing and promoting metastasis. Nat Rev Cancer 9: 40-55, 2009.

41. Jee BK, Park KM, Surendran S, et al: KAI1/CD82 suppresses tumor invasion by MMP9 inactivation via TIMP1 up-regulation in the H1299 human lung carcinoma cell line. Biochem Biophys Res Commun 342: 655-661, 2006.

42. SuzukiM,TachibanaI,Takeda Y,etal:TetraspaninCD9 negatively regulates lipopolysaccharide-induced macrophage activation and lung inflammation. J Immunol 182: 6485-6493, 2009.

43. Dua K, Williams TM and Beretta L: Translational control of the proteome: relevance to cancer. Proteomics 1: 1191-1199, 2001.

44. Jain MK and Zoellner C: Role of ribavirin in HCV treatment response: now and in the future. Expert Opin Pharmacother 11: 673-683, 2010

45. Culjkovic B and Borden KL: Understanding and targeting the eukaryotic translation initiation factor eIF4E in head and neck cancer. J Oncol 2009: 981679, 2009

46. Tamburini J, Green AS, Chapuis N, et al: Targeting translation in acute myeloid leukemia: a new paradigm for therapy? Cell Cycle 8: 3893-3899, 2009.

47. Panfilio S, D'Urso P, Annechini G, et al: Regression of a case of Multiple Myeloma with antiviral treatment in a patient with chronic HCV infection. Leuk Res Rep 2: 39-40, 2013. 